\title{
DI ANTARA UGATAMEE DAN INJIL: TRANSFORMASI TEOLOGI- TEOLOGI PRIBUMI DI TANAH PAPUA
}

\section{Ngurah Suryawan}

Jurusan Antropologi Fakultas Sastra dan Budaya Universitas Papua (UNIP A) Papua Barat e-mail:ngurabsuryawan@gmail.com

DOI: http://dx.doi.org/10.30983/islam_realitas.v2i1.182

\begin{abstract}
This article discusses the oral tradition in the form of indigenous theologies that are believed by many communities in Papua about their God as a life savior. Historically, the indigenous theology has an important role in the formation of knowledge about religion, customs, and culture that become orientation of their lives. Indigenous theologies in Papua is experiencing a transformation as the presence of religion. Tensions between indigenous theology and values of the gospel of Christianity particularly give serious impact on the religious orientation of the overall culture of the society. This article explores some teachings of indigenous theology, including the Ugatamee, Hai and Koreri along with their oral traditions and transformations the experienced.
\end{abstract}

Keywords: Tansformation of Religion, Indigenous Theology.

\section{Abstrak}

Artikel ini/mendiskusikan tradisi lisan berupa teologi-teologi pribumi yang diyakini oleh berbagai komunitas di tanah Papua tentang Tuhan mereka sebagai penyelamat kehidupan. Teologi pribumi tersebut dalam sejarahnya berperan penting dalam pembentukan pengetahuan tentang religi, adat, dan budaya yang menjadi orientasi kehidupan mereka. Teologi-teologi pribumi yang ada di tanah Papua mengalamai transformasi saat hadirnya agama. Ketegangan antara teologi pribumi dan nilai-nilai injil dalam agama Kristen khususnya berdampak serius terhadap orientasi religi sekaligus budaya masyarakat. Artikel ini mendalami beberapa ajaran teologi pribumi, diantaranya adalah Ugatamee, Hai dan Koreri beserta tradisi-tradisi lisannya dan transformasi-transformasi yang dialaminya.

Kata Kunci: Transformasi Agama, Teologi Pribumi.

\section{Latar belakang}

Adalah di Kampung Tadauto, Debey, Deiyai Papua kisah ini berawal. Sosok yang menginspirasi kelahiran gerakan teologi lokal bagi orang-orang Mee itu adalah Wodeyokaipouga Bobii yang kemudian menciptkan komunitas Komunitas Wodeyokaipouga yang mempelajari ajaranajaran tentang teologi lokal yang kontekstual yang mereka terapkan dalam kehidupan seharihari sebelum agama samawi hadir. Dalam dimensi yang lebih luas, ajaran teologi-teologi lokal yang "membadan" dalam kehidupan komunitas penganutnya adalah ekspresi teologis (kepercayaan) sekaligus kebudayaan tentang Ugatamee (Tuhan dalam bahasa Mee). Ajaran-ajarannya tidaklah berada di awangawang namun memiliki relasi historis dengan kehidupan sosial budaya mereka secara luas.

$$
\text { Perspektif teologi lokal dari }
$$

Wodeyokaipouga Bobii dan komunitasnya ini menjadi salah satu dari begitu banyak gerakangerakan teologi pribumi yang hingga kini masih hidup dan berkembang di tanah Papua. Di dalam ajaran dari gerakan-gerakan teologi pribumi ini terkandung konteks lokal yang 
sangat kuat. Hal ini ini disebabkan karena ajaran-ajaran ini tumbuh bersama dengan perjalanan religi komunitas lokal sehingga menyatu dengan emosi dan kisah perjalanan sedih dan gembira masyarakat. Konteks ini sangat penting dikedepankan untuk memahami gejolak komunitas di atas rumput yang tidak hanya berhubungan dengan teologi, tapi juga totalitas pergumulan manusia dengan lingkungan sekitarnya dalam berhadapan dengan modernisasi sebagaimana penelitian Miharja, saat ini masyarakat adat atau lokal berhadapan dengan arus modernisasi di segala aspek ${ }^{1}$. Pada tataran inilah sangat penting memperhatikan konteks sosial, termasuk di dalamnya kondisi kehidupan komunitas dari berbagai bidang kehidupan yang mendasari ekspresi teologis mereka.

Jika kita menelisik lebih dalam, keberagaman teologi lokal atau agama-agama pribumi di tanah Papua mengundang kesalahpenamaan sebagai "ajaran sesat" atau menghadap-hadapkannya dengan agama samawi yang hadir belakangan untuk membawa "terang" dan "peradaban". Kesalahpenamaan juga terdapat pada aliran sempalan dalam agama Islam sebagimana penelitian Burhanuddin bahwa ajaran agama diluar mainstream dikleim menyimpang dan sempalan ${ }^{2}$. Perspektif ini sangat melecehkan karena seolah-olah sebelumnya dengan teologi pribumi/lokal, komunitas pendukungnya berada dalam "kegelapan". Dalam wacana yang lebih luas, seperti ditengarai oleh Giay ${ }^{3}$,

\footnotetext{
1 Miharja, Deni, "Keberagaman Masyarakat Adat Cikondang Dalam Menghadapi Modernisasi", Islam Realitas: Journal of Islamic \& Social Studies, 1.1 2015, h 95-101.

2 Burhanuddin, Nunu, "Gerakan Sempalan Ahmadiyah: Dari Fenomena Urban Keagamaan Reformis Ke Messianis-Introversionis.", Islam Realitas: Journal of Islamic \& Social Studies, 1.2 2015, h. 145-154

3 Giay, Benny, "Zakheus Pakage and His Communities: Indigenous Religious Discourse, Sociopolitical Resistance, and Ethnohistory of the Me of Irian Jaya", PhD Dessertation Vrije Universiteit The Netherlands, 1995, h. 281.
}

aspek kekuasaan juga terjadi dalam bidang agama saat terjadinya pemaksaan terhadap kebijakan sosio-religius, politik, ekonomi dari luar dengan pendekatan yang konfrontatif. Komunitas-komunitas teologi pribumi inilah yang sering menjadi korbannya. Komunitas penganutnya diberlakukan dengan tidak manusiawi dengan rumahnya dibakar, dipenjarakan, dan mengalami kekerasan secara psikis. Saya meyakini-seperti juga yang dilakukan oleh Giay di atas bahwa sangatlah penting untuk memahami kemarahan, tangisan, serta keresahan dari para komunitas agama pribumi ini. Namun, itu saja tidak cukup. Langkah ke depan yang harus dilakukan adalah memahami gejolak mereka untuk melangkah ke depan.

Artikel ini diawali dengan memahami dinamika teologi-teologi pribumi yang terjadi di tanah Papua dengan berbagai kompleksitasnya. Dalam Suryawan, gerakangerakan yang dianggap gerakan kargo dan messianistic ini berkembang luas di tanah Papua sebagai respon dari berbagai situasi kegelisahan ekonomi, politik, dan "pembebasan" dalam kehidupan ${ }^{4}$. Bagian berikutnya penulis akan menguraikan salah satu gerakan dari orang Mee tentang komunitas Wodeyokaipouga Bobii mengenai kepercayaan mereka terhadap Ugatamee, Tuhan mereka dalam kepercayaan orang Mee. Pada bagian terakhir saya mencoba merefleksikan gejala-gejala transformasi yang dialami oleh teologi-teologi pribumi tersebut.

4 Suryawan, I Ngurah,. "Komin Tipu Komin: Elit Lokal dalam Dinamika Otonomi Khusus dan Pemekaran Daerah di Papua", dalam Jurnal Ilmu Sosial dan Ilmu Politik (JSP),Volume 15, Nomor 2, November 2011, h.140-153. Bandingkan juga dengan Suryawan, I Ngurah, "Politik Ruang (Pasar) dan Pemekaran Daerah: Siasat Rakyat Papua di Garis Depan Global", dalam Kritis, Jurnal Studi Pembangunan Interdisipliner, Vol. XXII No. 1 Februari - Juli 2012, h. 34- 35 


\section{Dinamika Teologi Pribumi}

Kepercayaan terhadap agama-agama pribumi di tanah Papua dikaitkan dengan gerakan-gerakan keselamatan, kultus kargo (cargo cult) dan pandangan messianistic yaitu pengharapan munculnya kebahagiaan dan kebebasan. Akar sejarah teologi pribumi ini memiliki sejarah panjang di Papua. Dalam Norget dan Devadutt, gerakan messianic ini secara umum lahir hampir bersamaan dengan masuknya injil dan nilai-nilai kekristenan yang masuk ke berbagai belahan dunia ${ }^{5}$. Hanya saja menurut Suryawan aliran ini masuk ke Papua tahun 1855 melalui zendeling Ottow dan Geisler. F.C Kamma, seorang zendeling yang bertugas di Papua ${ }^{6}$. Para peneliti pernah mencatat dalam sebuah laporannya yang dipublikasikan tahun 1863 bahwa gerakan cargo cult khususnya yang terjadi di Biak terjadi sekitar tahun 1855 dengan mitos Manarmakeri/Mansren Manggundi .

Gambar 1. Kesaksian-kesaksian Mendengar Suara Tuhan Yesus

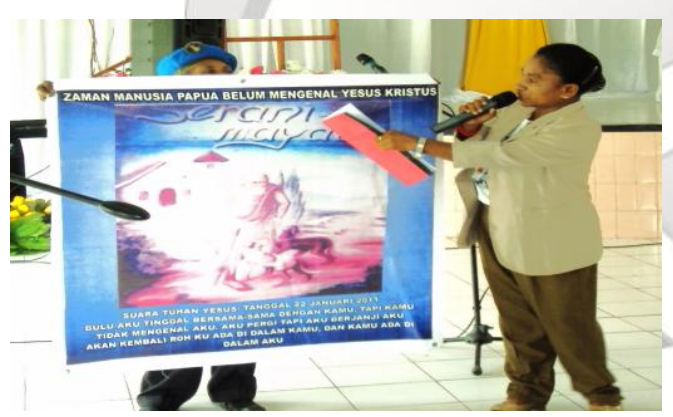

Selain Koreri dalam masyarakat Biak, di daerah pegunungan terdapat gerakan Hai pada

5 Norget, Kristin, "The Politics of Liberation: the Popular Church, Indigenous Theology, and Grassroots Mobilization in Oaxaca, Mexico", Latin American Perspectives, 24.5, 1997, h. 96-127. Bandingkan dengan Devadutt, Vinjamuri E., "What is an Indigenous Theology?", The Ecumenical Review, 2.1, 1949, h. 40-51.

${ }^{6}$ Suryawan, I Ngurah, "Politik Ruang (Pasar) dan Pemekaran Daerah: Siasat Rakyat Papua di Garis Depan Global..........., h. 34- 35

${ }^{7}$ Kamma, F. C., Koreri, Messianic Movements in The Biak-Numfor Area, (The Hague: Martinus Nijhoff, 1972), h. 20. Lihat juga, Strelan, J. G. dan Godschalk, J. A., 1989. Kargoisme di Melanesia (Jayapura: Pusat Studi Irian Jaya, 1989), h. 6 masyarakat Amungme (Damal) daerah Paniai juga berorientasi menuju "zaman bahagia". Gerakan atau pandangan hidup Hai seperti juga Koreri pada masyarakat Biak menurut argumentasi Gia) pada prinsipnya adalah sebagai sutu pandangan yang menjadi acuan hidup suku-suku bangsa pribumi di Tanah Papua (Provinsi Papua dan Papua Barat) ${ }^{8}$. Hai adalah suatu dambaan atau pengharapan akan kehidupan yang lebih baik, kehidupan yang penuh keadilan; kemakmuaran dan kehidupan yang didalamnya orang saling menghargai dan menjungjung tinggi kebersamaan. Dengan bahasa lain, Pamungkas menjelaskan Hai merupakan ungkapan/ekspresi masyarakat di Papua akan tatanan kehidupan yang penuh keadilan, kedamaian, dan kebahagian?.

Ekspresi dan ungkapan Hai adalah poros kebudayaan orang Amungme sehingga ekspresi Hai sangat dinamis tergantung konteks sosial budaya dan politik yang melingkupi orang Amungme. Oleh karena itulah, pengharapan akan Hai bergerak seiring dengan konteks social budaya, ekonomi, dan politik serta latar belakang historis orang Mee dalam transformasi sosial. Transformasi akan gerakan Hai ini akan terus terjadi seiring dengan konteks sosial budaya, ekonomi politik. Salah satunya adalah bagaimana resistensi orang Amungme terhadap investasi global PTFI (Freeport Indonesia) yang mengeruk kekayaan dan merusak lingkungan mereka. Harapan akan Hai menjadi jauh dari kenyataan dan perlawanan menjadi pilihannya.

Sementara Wege Bage dalam Suryawan pada masyarakat Mee di Pegunungan Tengah Papua memfokuskan bagaimana perlawanan dari seorang tokoh bernama Zakheus Pakage

8 Giay, Benny, "Zakheus Pakage and His Communities: Indigenous Religious Discourse, Sociopolitical Resistance,...h. 32

${ }^{9}$ Pamungkas, Cahyo, "Konflik Elit Lokal dalam Pembentukan Provinsi Irian Jaya Barat", Jumal Masyarakat Indonesia Lembaga Umu Pengetabuan Indonesia (LIPI) Indonesia, Jilid XXX. NO. 1. 2004, h. 12-43 
bersama komunitasnaya menolak ogai, penyiar agama Kristen berkebangsaan Barat dan atau orang dari luar Papua ${ }^{10}$. Studi Giay dan England mengungkapkan tentang sosok Zakheus Pakage dan Wege Bage mengungkapkan bahwa sangat penting melihat bagaimana respon teolog pribumi dan gerakan keagamaannya dalam melatakkan dasar bagi pengembangan teologi pribumi. Perintis gereja pribumi juga merumuskan Kekristenan sesuai dengan aspirasi dan kerangka berpikir sosialkeagamaan dari kelompok masyarakatnya ${ }^{11}$.

Zakheus Pakage ketika datang dari Makassar bulan Agustus 1950 membuat suasana berubah. Sebelumnya, hingga tahun sebelum Agustus 1950, masyarakat Suku Mee menolak Ogai dalam semua bentuk kebijakannya. Masyarakat ingin mengikuti ajaran Zakheus yang kemudian membentuk kampong-kampung Kristen menurut teologi dan kerangka pikir sosial keagamaan pribumi (orang Mee). Kampung-kampung Kristen dan pengikuti Zakheus inilah yang kemudian dinamakan Wege Bage oleh Ogai yang berarti orang-orang yang mengganggu dan merusak tatanan kehidupan masyarakat.

Transformasi yang terjadi adalah pertemuan antara teologi pribumi yang dikembangkan oleh Zakheus dengan teologi Kristen dan Ogai yang bertujuan untuk mencegah orang Papua dari cengkraman penguasa kegelapan dan membawanya ke terang injil ${ }^{12}$. Transformasi lainnya adalah

${ }^{10}$ Suryawan, I Ngurah, "Antropologi Gerakan Sosial: Membaca Transformasi Identitas Budaya di Kota Manokwari, Papua Barat" dalam Humaniora, Jurnal Budaya, Sastra, dan Bahasa Fakultas Ilmu Budaya Universitas Gadjah Mada, Yogyakarta Volume 23, Nomor 3, Oktober 2011, 290-300

${ }^{11}$ Giay, Benny, "Zakheus Pakage and His Communities: Indigenous Religious Discourse, Sociopolitical Resistance....., h.277. lihat juga England, John C. "Contextual Theology in Asian Countries: A Selected Annotated Bibliography." Practical Anthropology 12.4 (1984): 477-489

12 Giay, Benny, "Pembangunan Irian Jaya dalam Perspektif Agama, Budaya, dan Antropologi" eksistensi Hai dan Wege Bage di tengah transformasi sosial budaya yang berlangsung pada masyarakat Mee. Laksono menjelaskan pada interkoneksi teologi pribumi dan transformasi sosial yang berlangsung inilah dinamika dan kebudayaan rakyat Papua akan terbentuk ${ }^{13}$.

\section{Gambar 2. Manarmakeri (Koreri), Tuhan menurut Komunitas Etnik Biak di Papua}

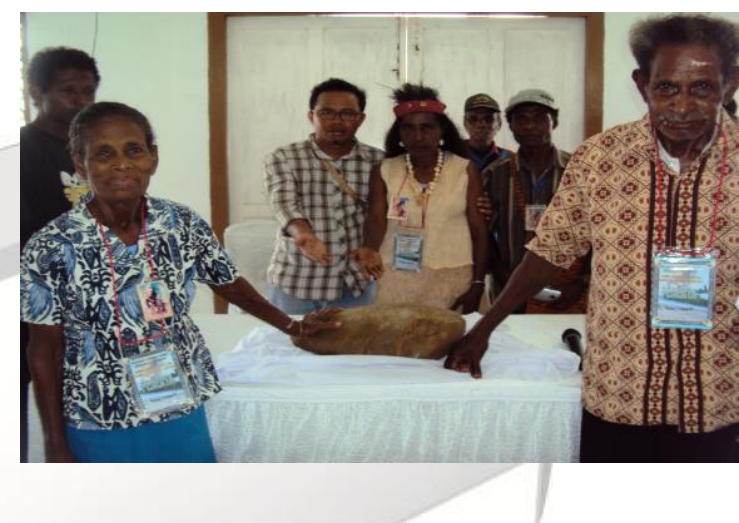

\section{Inspirasi Wodeyokaipouga Bobii}

Buku yang ditulis oleh Frans Bobii ini membawa kita untuk menyelami pengalaman religius yang dialami oleh Wodeyokaipouga Bobii, salah satu penggerak agama lokal di Kampung Tadauto, Debey, Kabupaten Deiyai Provinsi Papua. Pada masyarakat Mee, filosofi kehidupannya bersandar pada pondasi Totamana, terdiri dua kata yakni; Tota $=$ sudah ada, telah ada, mana=berita, suara, kabar, maka secara harafiah dapat dijelaskan sebagai suatu yang sudah ada sejak sebelumnya. Totamana bisa diartikan sebagai suatu kabar yang sudah ada sejak lama. Sementara Touyemana terdiri dari tiga kata; Tou=tinggal, berdiam, duduk $Y_{e}=$ suatu keheranan, heboh dan Mana $=$ suara, kabar, berita. Touyemana dengan demikian adalah sebuah pandangan hidup yang berprinsip pada mendudukkan

makalah dalam Simposium Masyarakat dan Pembangunan di daerah Irian Jaya yang dilaksanakan BPC GMKI Jayapura tahun 1996, h. 40

${ }^{13}$ Laksono, P.M., "Tanpa Tanah, Budaya NirPapan, Antropologi Antah Berantah" , Jumal Antropologi Indonesia, Vol 12, 2002, h. 45-64 
suatu sesuatu pada tempat semua, sebagai ajakan moral, agar tetap dan akan hidup. Toutamana terdiri dari kata Tou=tinggal, berdiam, duduk, $T a=$ keheranan terhadap suatu. Mana=berita, suara, kabar. Jadi Toutamana mengandung arti bahwa suatu kabar gembira itu ada sepanjang sejarah hidup manusia. Sementara Tounemana terdiri dari kata Tou=tinggal berdiam, duduk tersembunyi, $\mathrm{Ne}=$ perintah atas dirinya untuk tinggal. Mana $=$ Berita, kabar, suara. Jadi dengan demikian Tounemana adalah suatu hukum yang tidak mau pergi dan mengikat kepada manusia sebagai penganutnya ${ }^{14}$.

Dalam konteks yang lebih luas, Bobii (2016) melanjutkan bahwa menurut ajaran agama pribumi, Totamana mengungkapkan kerinduan akan Tuhan melalui beberapa ungkapan secara spontan, walaupun mereka belum mengenalnya, dan mengetahui melalui tanda-tanda alam yang terjadi dalam situasi hidup Mereka. Misalnya mengenal Tuhan berdasarkan tanda-tanda alam yang diwujudnyatakan melalui ada sesuatu yang menjadikan dunia dan manusia (kokeewadome, kokaumiyomee), artinya diatas langit ada orang yang mencipta dan di dalam tanah ada manusia yang sedang mengayomi kita manusia. Berbagai bentuk pujaan dan doa; serta kepercayaan mengawasi mereka.

Filosofi dan pondasi kehidupan orang Mee dalam hubungannya dengan Ugatame (Tuhan) inilah yang dijadikan dasar oleh Wodeyokaipouga Bobii untuk menyebarkan karya teologis sekaligus juga karya sosialnya. Simaklah bagaimana pandangan Wodeyokaiponga Bobii tentang Tuhan Allah dalam bahasa Mee sebagaimana dalam Suryawan:

${ }^{14}$ Suryawan, I Ngurah,. “ Desain Besar Penataan Daerah dan Dinamika Identitas Budaya di Provinsi Papua Barat", Kritis, Jurnal Studi Pembangunan Interdisiplin, Vol. XXIII No. 3, 2014, h.140-153.
Edoga puki paki ko uwo egun na beu momogi na beu, yitiyouto, yimuna beu kidi tota. Uwo modo kiyake toba yokaa pamakita.Toba mado kiyake udi yoka pamakita. Udi modoo kiyake me yokaa woo pamakita. Okai kii me kidiki ekako enato bapa. Yamake epa ugaina epi. Maki ugaina epi. Maikai ugaina epi, kiyake ugatame ekaa motita ${ }^{15}$.

Bagi Wodeyokaipouga Bobii, Allah pada mulanya air. Air itu bersih dan murni dan tidak ada ujung dan pangkalnya. Air itu mengandung dan melahirkan berudu. Berudu mengandung dan melahirkan udang. Udang mengandung dan melahirkan manusia. Manusia itu disebut Enato Naitai (Bapak Tunggal/Bapa Yang Esa). Dia yang berkuasa menciptakan langit, bumi dan lautan dan segala yang ada di dalamnya, maka Dia di beri julukan Ugatame (Allah menurut Suku Mee) artinya Pencipta.

Nilai-nilai filosofis dari ajaran Wodeyokaipouga Bobii diikuti dengan menterjemahkannya dalam syair doa-doa dalam lagu. Di dalam lagu-lagu yang diajarkannya bermakna pujian, penyembahan, dan juga lagu yang memohon keselamatan jasmani rohani, kerinduan akan memperoleh hidup yang kekal, dan juga memuji kekuatan Allah. Ayat-ayat teologi lokal yang di ajarkannya ada yang berhubungan dengan mulai dari kisah penciptaan diakhiri dengan ajakan merendahkan diri mengikuti Tuhan.

Selain dalam karya teologis, Wodeyokaipouga Bobii juga berkarya secara sosial. Diantaranya adalah kegiatan pembersihan dan pemagaran lingkungan ini dimulai sejak tahun 1940-an. Sebelumnya ajarannya dimulai sejak tahun 1920-an. Wodeyokaipouga Bobii mengejawantahkannya menjadi dua belas jenis kegiatan sehingga

15 Suryawan, I Ngurah, "Tanah Dibutuhkan Tapi Orang Tidak: Transformasi Masyarakat Adat dalam Perspektif Etnografi dan Sejarah Sosial", dalam Kritis, Jumal Studi Pembangunan Interdisipliner, Vol. XXII No. 2 Juli -Desember 2013, h. 231- 250 
kerap kali menyebutnya dengan sebutan Gaa bado wiyamagati kouko tenayaikai. Kedua belas macam kegiatan ini jangan dilalaikan walaupun. Kedua belas macam kegiatan itu di antaranya; pemagaran lingkungan, pembersihan lingkungan, pembangunan rumah berpola asrama, pesta bersama atau makan bersama, lbadah bersama atau sembahyang bersama, pembuatan kolam sampah, pembuatan tempat toilet, perkebunan, pertanian, perikanan darat, reboisasi atau penghijauan, serta pengumpulan dana. Jangan dilupakan pula adalah kegiatan untuk pemberdayaan ekonomi komunitasnya dalam program perkoperasian masyarakat. Demi meningkatkan kesejahteraan masyarakat itu telah ditetapkan tiga jenis kegiatan yaitu usaha bersama, pengumpulan dana dan pengadaan kios koperasi masyarakat.

Kerangka kerja teologis dan social yang diterapkan oleh Wodeyokaipouga Bobii tentunya mengalami tantangan terutama dari Ogai (orang luar/asing) yang selalu berpandangan bahwa hanya merekalah yang memiliki kebenaran. Dalam konteks transformasi sosial budaya yang terjadi, pengaruh penginjilan, gereja, dan pendidikan sangatlah penting perannya. Dalam catatan Bobii, tahun 1965 merupakan tahun peradabaan baru yang merubah tatanan sosial budaya masyarakat. Seiringnya perkembangan zaman, pihak gereja Katolik dan Kigmi membuka sekolah SD YPPGI di Widuwakiya dan SD YPPK di Wagomani. Yohanes Gobay (Mantan Ketua Wilayah GKII Papua, Pdt. Yohanes Gobay, S.Th), ditugaskan sebagai guru pertama di SD YPPGI Widuwakiya setelah selesai dari SGB (Sekolah Guru Bawah). Sementara di pinggiran Danau Tigi terdapat SD YPPGI Bomou, SD YPPGI Onago, SD YPPGI Gako Kebo dari kalangan Gereja Kingmi waktu itu sudah dibuka. Setelah orang Debey belajar membaca dan menulis, mereka yang bisa membaca dijadikan tenaga pengajar bagi warga buta aksara.

Pada momen ini sebenarnya sudah terjadi fragmen-fragmen perubahan di tengah komunitas Wodeyokaipouga Bobii saat merespon hadirnya agama, birokrasi, pendidikan, dan tentu saja perubahan yang dibawa oleh arus migrasi manusia di seluruh pelosok tanah Papua. Menarik untuk mencermati bagaimana arus transformasi ini direspon oleh para penganut teologi-teologi lokal.

\section{Kesimpulan}

Di tengah situasi transformasi sosial budaya yang tak terhindarkan, memperhatikan ajaran-ajaran teologis dan praktik-praktik ritual dan social budaya dari komunitas agama pribumi menjadi sangat menarik. Fragmen tersebut akan memberikan gambaran jejak perubahan sosial budaya yang terjadi. Dalam teologi-teologi pribumi, kita telah dibawa untuk memahami bagaimana pandangan religi telah hidup di tengah masyarakat dan mempengaruhi kehidupan banyak orang. Namun, kita semestinya harus terus berefleksi bahwa keseluruhan pengalaman religi dari manusia adalah merupakan jejak historis sekaligus juga budaya yang patut dipahami dan dihargai untuk penghormatan terhadap Tuhan dan manusia itu sendiri.

Oleh sebab itulah mengembangkan sikap yang apresiatif, terbuka, toleran, serta mengedepankan pendekatan dialog teologis sangatlah penting dilakukan. Selain akan mengembangkan pemikiran untuk terbuka terhadap pandangan teologis berbeda, yang lebih penting adalah memperkaya pengetahuan teologis maupun sosio-kultural terhadap sejarah dan perkembangan teologi-teologi lokal. Inspirasi dan pengetahuan teologis dan sosial budaya akan membawa kita kepada pemahaman tentang dinamika teologis maupun sosio-kultural orang-orang Papua 
yang sedang berubah. Transformasi (perubahan) sosial-budaya yang tak terhindarkan di tanah Papua menuntut pemahaman yang utuh dan penghargaan terhadap keberadaan komunitas teologi pribumi ini.

Kekayaan pengetahuan tentang pengetahuan teologis dan sosio-budaya dari agama-agama pribumi di tanah Papua sangatlah penting untuk dituliskan. Jika tidak akan tertelan tradisi oral (bertutur) yang melekat dalam hidup orang-orang Papua secara umum. Saya akan berusaha untuk membingkai dan mewacanakan dua isu penting dalam esai sederhana ini yaitu tentang dinamika teologi pribumi dan transformasi sosial budaya yang menyertainya.

\section{Daftar Pustaka}

Buku

Giay, Benny, -----, Kargoisme di Irian Jaya (Sentani: Region Press, 1986).

------, Menuju Papua Baru: Beberapa Pokok Pikiran sekitar Emansipasi Orang Papua (Jayapura: Deiyai/Els-ham Papua, 2000).

Kamma, F. C., Koreri, Messianic Movements in The Biak-Numfor Area (The Hague: Martinus Nijhoff, 1972).

Strelan, J. G. dan Godschalk, J. A., Kargoisme di Melanesia (Jayapura: Pusat Studi Irian Jaya, 1989)

\section{Jurnal dan Makalah Ilmiah}

Burhanuddin, Nunu, "Gerakan Sempalan Ahmadiyah: Dari Fenomena Urban Keagamaan Reformis Ke MessianisIntroversionis", Islam Realitas: Journal of Islamic \& Social Studies, Vol. 1, No. 2, 2015.

Devadutt, Vinjamuri E., "What is an Indigenous Theology?", The Ecumenical Review, 2.1, 1949.

England, John C., "Contextual Theology in Asian Countries: A Selected Annotated Bibliography", Practical Anthropology, 12.4,

Giay, Benny, "Masyarakat Amungme Irian Jaya, Modernisasi dan Agama Resmi: Sebuah Model Pertemuan", Jurnal Deiyai, Januari-Februari 1996.

-----, "Pembangunan Irian Jaya dalam Perspektif Agama, Budaya, dan Antropologi", makalah dalam Simposium Masyarakat dan Pembangunan di daerah Irian Jaya yang dilaksanakan BPC GMKI Jayapura tahun 1996.

"Masyarakat Amungme (Irian Jaya), Modernisasi dan Agama Resmi: Sebuah Model Pertemuan", dalam Kisah dari Kampung Halaman. Yogyakarta: Interfidei, 1996.

, "Zakheus Pakage and His Communities: Indigenous Religious Discourse, Sociopolitical Resistance, and Ethnohistory of the Me of Irian Jaya", PhD Dessertation Vrije Universiteit The Netherlands, 1995.

Laksono, P.M., "Tanpa Tanah, Budaya NirPapan, Antropologi Antah Berantah", Jumal Antropologi Indonesia, Vol 12, 2002.

Miharja, Deni, "Keberagaman Masyarakat Adat Cikondang Dalam Menghadapi Modernisasi", Islam Realitas: Journal of Islamic \& Social Studies, Vol. 1, No. 1, 2015.

Norget, Kristin, "The Politics of Liberation: the Popular Church, Indigenous Theology, and Grassroots Mobilization in Oaxaca, Mexico", Latin American Perspectives 24.5, 1997.

Pamungkas, Cahyo, "Konflik Elit Lokal dalam Pembentukan Provinsi Irian Jaya Barat", Jumal Masyarakat Indonesia Lembaga Umu Pengetahuan Indonesia (LIPI) Indonesia, Jilid XXX. No. 1. 2004.

Radongkir, Daniel Charles Elisa, . "Transformasi Gerakan Koreri pada Orang Biak di Kecamatan Biak Kota Kabupaten Biak Numfor (Suatu Tinjauan Antropologis)", Skripsi pada Jurusan Antropologi, Fakultas Ilmu 
Sosial dan Ilmu Politik Universitas Cenderawasih, 2001.

Rutherford, Danylin, “The White Edge of the Margin: Textuality and Authority in Biak, Irian Jaya, Indonesia", dalam American Etnologist, Vol. 27, No. 2 May, 2000.

Suryawan, I Ngurah, "Antropologi Gerakan Sosial: Membaca Transformasi Identitas Budaya di Kota Manokwari, Papua Barat", dalam Humaniora, Jurnal Budaya, Sastra, dan Bahasa Fakultas Ilmu Budaya Universitas Gadjah Mada, Yogyakarta Volume 23, Nomor 3, Oktober 2011.

-----, "Tanah Dibutuhkan Tapi Orang Tidak: Transformasi Masyarakat Adat dalam Perspektif Etnografi dan Sejarah Sosial", dalam Kritis, Jumal Studi Pembangunan Interdisipliner, Vol. XXII No. 2 Juli Desember 2013.

-----, "Politik Ruang (Pasar) dan Pemekaran Daerah: Siasat Rakyat Papua di Garis Depan Global", dalam Kritis, Jurnal Studi Pembangunan Interdisipliner, Vol. XXII No. 1 Februari - Juli 2012.

"Desain Besar Penataan Daerah dan Dinamika Identitas Budaya di Provinsi Papua Barat", Kritis, Jurnal Studi Pembangunan Interdisiplin, Vol. XXIII No. 3, 2014.

------, "Komin Tipu Komin: Elit Lokal dalam Dinamika Otonomi Khusus dan Pemekaran Daerah di Papua", dalam Jurnal Ilmu Sosial dan Ilmu Politik (JSP), Volume 15, Nomor 2, November 2011. 